\title{
Brittle Failure Resistance of Steels and Weld Metals for Pressure Vessels*
}

\author{
By Václav PILOUS** and Karel LÖBL***
}

\begin{abstract}
Synopsis
The effects of hydrogen introduced into a welded joint particularly from misture of filler material used during welding of heavy gage steels are followed. The results are compared with the effects of hydrogen introduced by controlled electrolytic hydrogenization as a simulation of the hydrogen diffusion from cooling water into welded joints during the reactor operation. The quality of welded joints is shown to be unfavourably influenced by combined effects of hydrogen embrittlement and phosphorus segregaticn along grain boundaries. The optimum annealing for regeneration can be effectively performed at temperatures about $500^{\circ} \mathrm{C}$, when the intergranular concentration of phosphorus and sulphur is minimum and the hydrogen content decreases depending on the temperature and activity of surrounding environment.
\end{abstract}

Key words : brittle failure; weld joint; hydrogen; grain boundary segregation; chromium, nickel, molybdenum and vanadium steel; crack propagation; stress intensity amplitude; annealing for regeneration.

\section{Introduction}

In nuclear engineering the emphasis is put on the integrity of welded joints during steel welding. Welded joints must be free of defects resulting from hot, cold, annealing and undercladding crack mechanisms. Extremely high are the demands put on welded joint characteristics especially on required mechanical, physical and chemical properties, structural stability, corrosion resistance and radiation damage.

The aim of the work is to follow up:

i) the effect of metallurgical hydrogen introduced into welded joints from the moisture of the filler materials during welding of heavy gage steels.

ii) the possibility of lowering hydrogen content in welded joints by application of preheating, preheating and low-temperature tempering, and high-temperature tempering,

iii) simulation study of the effect of hydrogen that diffuses from cooling water into the welded joint during the reactor operation, by electrolytic hydrogen charging, and

iv) the effect of phosphorus and sulphur microsegregation along grain boundaries and the optimum temperature of annealing for regeneration.

\section{Material and Experimental Procedures}

The weldability was studied on $30 \sim 120 \mathrm{~mm}$ thick plates of $\mathrm{GrNiMoV}$ high-strength tempered steels with $0.16 \% \mathrm{C} ; 0.42 \% \mathrm{Mn} ; 0.32 \% \mathrm{Si} ; 0.012 \% \mathrm{~S}$; $0.014 \% \mathrm{P} ; 2.1 \% \mathrm{Cr} ; 1.25 \% \mathrm{Ni} ; 0.62 \% \mathrm{Mo}$; and
$0.1 \% \mathrm{~V}$. Automatic submerged-arc welding was employed for producing a $\mathrm{CrNiMoV}$ welded joint with $0.14 \% \mathrm{C} ; 0.52 \% \mathrm{Mn} ; 0.34 \% \mathrm{Si} ; 0.014 \% \mathrm{~S}$; $0.015 \% \mathrm{P} ; 2.3 \% \mathrm{Cr} ; 1.28 \% \mathrm{Ni} ; 0.68 \% \mathrm{Mo}$; and $0.11 \% \mathrm{~V}$. Tekken and Implant laboratory weldability tests on $30 \mathrm{~mm}$ thick plates were used and applied in a wide range according to parametric equations for the numerical analysis of preheat temperature calculations. ${ }^{1-3)}$

The analysis of undercooled austenite anisothermal TTT diagrams of the present steels (see Fig. 1) shows that the microstructure of heat affected zone may be martensitic-bainitic and in a limited case of higher preheating temperatures or electroslag welding ferritic-bainitic, respectively. ${ }^{4)}$ The diagram was evaluated by dilatometry of the pieces $(3 \mathrm{~mm}$ diameter and $15 \mathrm{~mm}$ length) cooled from $1250^{\circ} \mathrm{C}$. As a consequence, the steel would be susceptible to hydrogen induced cold cracks.

Electrolytical hydrogenization of the test pieces was performed in sulphuric acid with $20 \mathrm{ppm} / l$ of $\mathrm{As}_{2} \mathrm{O}_{3}$ as a stimulator. The current densities were $1 \sim 2000 \mathrm{Am}^{-2}$, hydrogenization times $1 \sim 30 \mathrm{~h}$. The contents of metallurgically and electrolytically introduced hydrogen were determined as a total atomic and molecular hydrogen in samples $(5 \mathrm{~mm}$ diameter and $8 \mathrm{~mm}$ length) by inert gas fusion gas chromatography. To ensure the authenticity of results the samples were transported in boxes with inner tem-

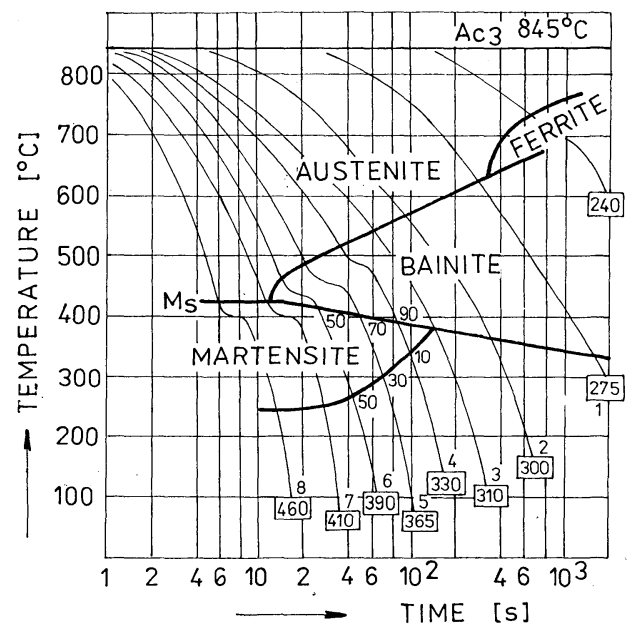

Fig. 1. TTT diagram of CrNiMoV steel with $0.16 \% \mathrm{C}$; $0.42 \% \mathrm{Mn} ; 0.32 \% \mathrm{Si} ; 2.10 \% \mathrm{Cr} ; 1.25 \% \mathrm{Ni}$; $0.62 \%$ Mo; $0.10 \% \mathrm{~V}$. (mass \%)

* Manuscript received on October 27, 1986; accepted in the final form on April 15, 1987. (C) 1987 ISIJ

** Technical University, Plzeň, Czechoslovakia.

*** Technical University, Prague, Czechoslovakia. 
perature of $-78^{\circ} \mathrm{C}$. The reproducibility of the analysis was checked by comparison of the values obtained from another apparatus; the differences were about $12 \%$. Hydrogenization was also applied to tensile test pieces $(5 \mathrm{~mm}$ in diameter and $20 \mathrm{~mm}$ length).

Phosphorus and sulphur segregation on grain boundaries was proved by Auger spectroscopy. The analysis was performed on the specimen $(3 \mathrm{~mm}$ in diameter) fractured in vacuum at $20^{\circ} \mathrm{C}$.

The dependence of the crack propagation rate on the stress intensity factor amplitude was evaluated by using the test according to Standard SCHENCK PSB 25 with hydraulic system $250 \mathrm{kN}$. The crack propagation was observed on samples with $50 \times$ $10 \mathrm{~mm}$ in cross-section and $200 \mathrm{~mm}$ gage-length with optical microscopy. Mechanical properties were determined on a hard tensile testing machine with a capacity of $10 \mathrm{kN}$ at a strain rate $8.3 \times 10^{-4} \mathrm{~s}^{-1}$. Fracture surface (after static and fatigue tests) were examined by an analytical scanning electron microscope.

\section{Degradation Processes of Pressure Vessels in Manufacture and Service Conditions}

Hydrogen embrittlement is characterized by losses of plasticity particularly of contraction ductility and fracture toughness.

The present experiments were oriented to the comparison of consequences of both production technology factors and service conditions. To determine the welding effects the plates $(120 \mathrm{~mm}$ thick and $1000 \mathrm{~mm}$ length) were welded by automatic submerged-arc welding with preheating of $150^{\circ} \mathrm{C}$. After welding, one-third of the weldment was annealed at $300^{\circ} \mathrm{C}$ for $6 \mathrm{~h}$, one-third at $680^{\circ} \mathrm{C}$ for $1 \mathrm{~h}$ and the rest without thermal treatment. Test samples for evaluation of metallurgically introduced hydrogen content were taken in the middle of the welded joint at a depth of $20-\mathrm{mm}$ step along the thickness direction. The hydrogen contents are summarized in Table 1 from which it is evident that the content of metallurgically introduced hydrogen decreases with increasing depth below the welding surface from A to $\mathrm{E}$. The hydrogen content reaches up to $4.5 \mathrm{~cm}^{3} /$ $100 \mathrm{~g}$ for $120-\mathrm{mm}$ thickness. The hydrogen content of $4.5 \mathrm{~cm}^{3} / 100 \mathrm{~g}$ is rather high, because such tests were carried out to evaluate the hydrogen content of welded joint in dependence on flux backing during welding. The results of hydrogen content determination in the weld metal of $30 \mathrm{~mm}$ thick plates (Tekken and Implant tests) in dependence on flux moisture are shown in Fig. 2. Detailed test data are given elsewhere ${ }^{4)}$ by the present author.

Table 1 and Fig. 2 reveal that for welding it will be necessary to use filler materials with a very low hydrogen content throughout the whole temperature regime and subsequent thermal treatment. The hydrogen in atomic state will penetrate by diffusion into grains on the surface of weld metal or base material and will raise the surface stress of grains. Furthermore, the cohesion strength between grains
Table 1. Hydrogen content in $120 \mathrm{~mm}$ thick joints welded with preheating at $150^{\circ} \mathrm{C}$, annealed at $300^{\circ} \mathrm{C}$ and tempered at $680^{\circ} \mathrm{C}$.

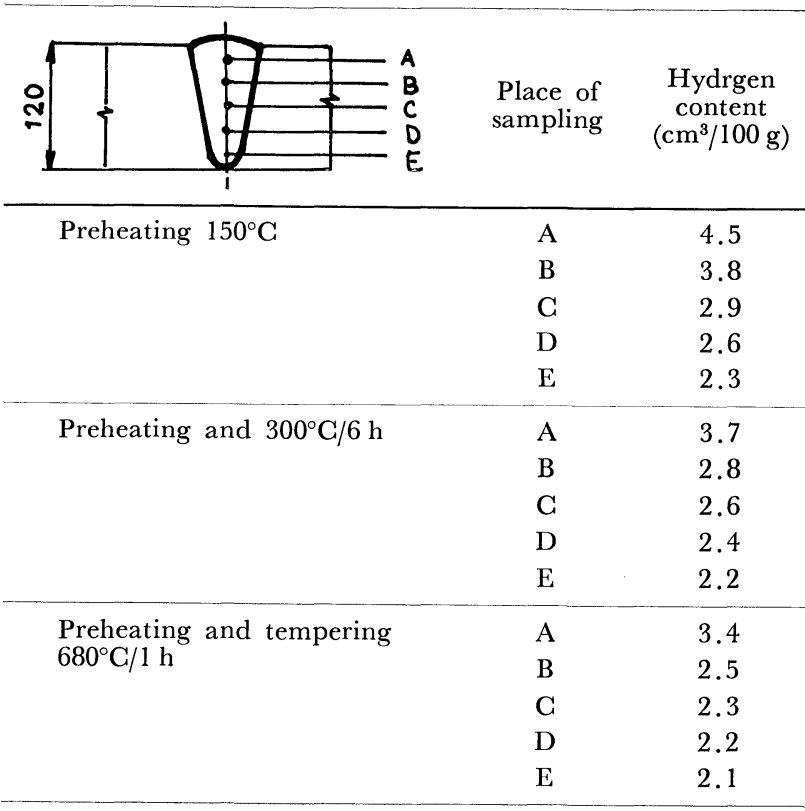

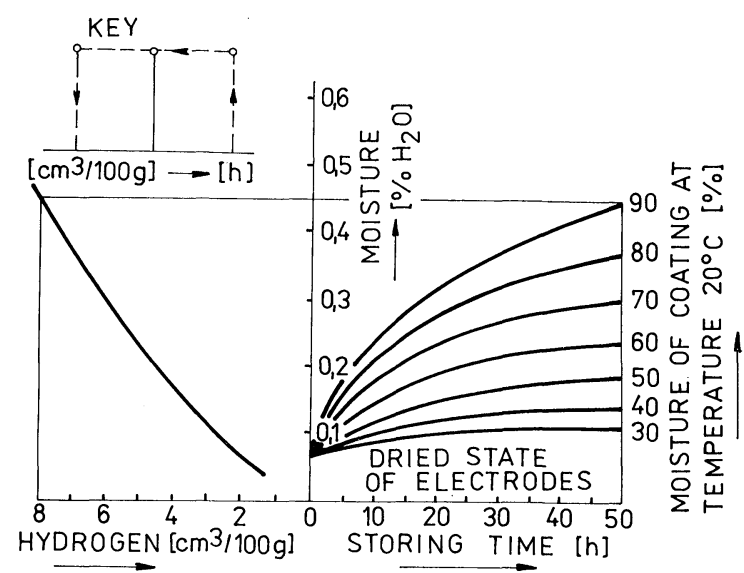

Fig. 2. Dependence of welded joint metallurgical hydrogen content on flux moisture (of surrounding environment).

can be weakened because of the combined effects of hydrogen and transformation stress.

From the point of service factors of pressure vessel welded joints, the hydrogen in atomic state is decisive because it is capable of diffusion from cooling water into the pressure vessel steel according to the chemical concentration gradient generated by electrolysis of clean water. ${ }^{5)}$ Although the inner wall of pressure vessel was protected against the corrosion environment by anti-corrosion austenitic $\mathrm{GrNi}$ weld cladding, it was necessary to evaluate the effect of hydrogen that originated during the reactor operation on the GrNiMoV steel welded joint properties. Contraction values of weld metals are dependent on metallurgically and electrolytically introduced hydrogen as shown in Fig. 3; the contraction decreases below $20 \%$ with introduction of electrolytically hydrogen as small as $5 \mathrm{~cm}^{3} / 100 \mathrm{~g}$. From contraction values $v s$. hydrogen content dependence diagram, it is evident 


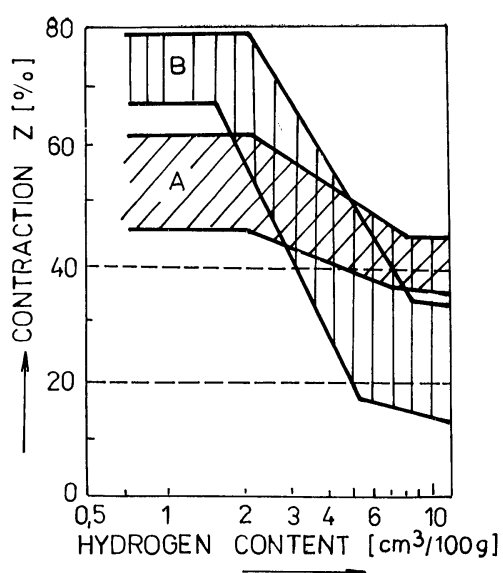

Fig. 3. Welded joint contraction values dependent on metallurgically (A) and electrolytically (B) introduced hydrogen content.

that the hydrogen concentration up to $2 \mathrm{~cm}^{3} / 100 \mathrm{~g}$ has no significant effect on the fracture process. Fracture surface analysis has shown that the fracture accompanied plastic deformation. Above $3 \mathrm{~cm}^{3} /$ $100 \mathrm{~g}$, brittle fracture occurred with quasi-cleavage, which was characteristic of hydrogen embrittlement. ${ }^{4,6)}$ If the hydrogen embrittlement arose significantly at a hydrogen content higher than 2 or $2.5 \mathrm{~cm}^{3} / 100 \mathrm{~g}$ (see Fig. 3) according to the results of service condition applications, the above mentioned content can be referred as a critical value of an electrolytical hydrogen.

In the study of the metallurgical processes of surface segregation in low-alloy steels and weld metals for power engineering, it was proved ${ }^{4,6}$ that the process is controlled by such factors as corresponding to corrosion cracking at an extremely low loading frequency in water in terms of crack propagation rate and stress intensity factors. On the basis of the push-pull testing results, the crack growth process is thought to be controlled mostly by diffusion of hydrogen atoms at working temperature, when the time necessary for hydrogen diffusion is sufficient. Besides the hydrogen effect, the susceptibility to intercrystalline damage is influenced also by the development of microsegregations of detrimental impurities among which phosphorus can be important at the pressure vessel working temperatures.

Surface segregation evaluated by Auger emission spectroscopy (see Fig. 4) confirmed the conclusions given in a previous report. ${ }^{6}$ ) The present study suggests that comprehensive understanding of steel characteristics requires assessment of the effects of external environment, at which combined contributions of hydrogen and microsegregations of detrimental impurities especially of phosphorus occurred at working temperatures of $325^{\circ} \mathrm{C}$. Unfavourable interference of detrimental impurities leads to sensitization of weak points in the microstructure and to weakening of grain boundary cohesive strength. Important information can be gained from Fig. 4. That stress relief annealing at the temperatures of 650 or $580^{\circ} \mathrm{C}$ respectively, could cause an increased tendency to

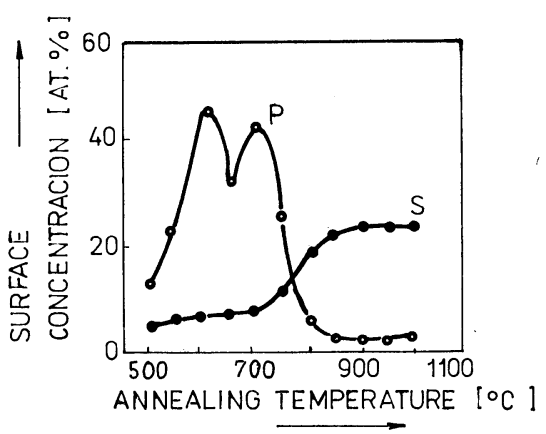

Fig. 4. Results of phosphorus and sulphur surface segregation in dependence on annealing temperature $(10 \mathrm{~h})$.

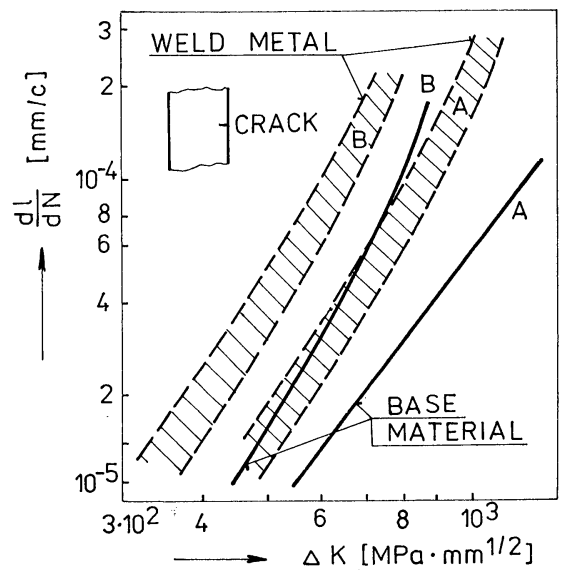

A: Without hydrogenization

B : With electrolytical hydrogenization

Fig. 5. Surface crack development in the CrNiMoV steels and weld metals.

phosphorus embrittlement which could show greater part in intercrystalline cleavage failure. The unfavourable consequence of detrimental elements segregation was proved by Auger spectroscopy. Together with hydrogen it would result in substantial degradation of material characteristics especially that of cohesive strength along grain boundaries. From Fig. 4 are evident the mutual interactions between phosphorus and sulphur segregation and very important conclusion for the case of regeneration annealing results. The regeneration annealing is optimum to perform at temperatures about $500^{\circ} \mathrm{G}$, when the surface concentration of phosphorus and sulphur is minimum.

The crack in service conditions was proved to propagate through the path, where corrosion potential and hydrogen content are brought to be highest in steelmaking and welding processes. It refers to the welded joints in active section, which in case of damaging of protective cladding can be strained additionally as a consequence of service conditions.

Results are given in Fig. 5, where the dependence is shown for cyclic fatigue loading of the $\mathrm{CrNiMoV}$ weld metal and steel specimens with a simulated surface crack. Further, the results are included for fatigue stressed specimens after electrolytic hydrogenization up to $4 \mathrm{~cm}^{3} / 100 \mathrm{~g}$ of hydrogen. The 
tests at a frequency of $34 \mathrm{~Hz}$ and $\mathrm{R}=0$ proved that cracks propagated along the dependences given in Fig. 5 and corresponded to the data given in. ${ }^{7)}$

\section{Discussion of Results}

An important conclusion of the present study is necessity to give a special attention to the hydrogen content in a weld metal after welding and cladding with filler materials stored and baked differently. The reason for it is that the hydrogen increases substantially the susceptibility to cold cracking of welded joints, especially in the case of hardened structures (see Fig. 1). Therefore, it is necessary to bake filler materials properly, as demonstrated in Fig. 2, where the hydrogen content in weld metal is given in dependence on flux moisture during automatic submergedarc welding of $\mathrm{GrNiMoV}$ steels.

For completeness dependence of the contraction values on the hydrogen content are evaluated in the CrNiMoV weld metal from electrode coating moisture and after electrolytic hydrogenization. Figure 3 shows that at the same hydrogen contents no significant loss of contraction values is apparent in comparison with the electrolytically hydrogenized weld metal. From Fig. 3 and Table 1, it follows that a uniform distribution of metallurgical hydrogen in a supersaturated state throughout the cross-section and length of weld metal, in contrast to electrolytically hydrogenized specimens, where the leading role of hydrogen embrittlement at interfaces such as grain boundaries and coarse inclusions was proved to be characterized by the heterogeneous state of material and the hydrogen pressure (activity) in material and surrounding environment. The present work established that the hydrogen content increased with increasing thickness of welded joints up to $120-\mathrm{mm}$ where a critical hydrogen content was attained to develop brittle quasi-cleavage fracture owing to hydrogen embrittleness in the case of electrolytic hydrogenization (see Table 1).

Hydrogenization up to $4 \mathrm{~cm}^{3} / 100 \mathrm{~g}$ leads to a considerable increase in crack propagation rate in dependence on the stress intensity factor range, which is shown by the curve displacement to the left. (see Fig. 5) and by intercrystalline fractures identified by scanning electron microscopy.

The present results suggest the need to minimize the surface cracks in pressure vessel walls because brittle failure occurs more rapidly at fatigue stress in service conditions with hydrogen environment than in usual service conditions. The content of hydrogen introduced to both weld metal and undercladding zones should be kept at a low level by subsequent baking of filler materials and by suitable annealing processes, and the effect of service conditions should be reduced to the lowest measure in this way. ${ }^{8)}$

\section{Conclusion}

The paper deals with brittle failure resistance of welded joints and high-strength $\mathrm{CrNiMoV}$ steels for pressure vessels.

The effect of metallurgical hydrogen introduced particularly from moisture of filler material used during heavy gage steel welding is studied. The results are compared with the effect of hydrogen introduced into the weld metal by controlled electrolytic hydrogenization as a simulation of service conditions. The conclusion is that the welded joint quality could be unfavourably influenced by interfering effect of hydrogen and phosphorus segregations along grain boundaries. It is necessary to minimize the hydrogen content in weld metal and to avoid subcladding crack initiation and formation and protective cladding overlay reduction. Undercladding initiations and surface defects are generated at interfaces for hydrogen diffusion, where damaging or substantial decreasing of cohesive strength between grains occurs. Annealing for regeneration is recommended at temperatures about $500^{\circ} \mathrm{C}$, when the phosphorus and sulphur surface segregation are minimum and the hydrogen content decreases according to time, temperature and activity of surrounding environments.

\section{REFERENCES}

1) I. Hrivnak: Weldability of Steels, ALFA, Bratislava, (1979).

2) R. Bruscato: Weld. J., 53 (1983), No. 2, 57.

3) G. J. Karr and R. J. Olsen: SOCAL Mater. Labor. Rep., 8025, 43, (1971).

4) V. Pilous: Zvaranie, 35 (1986), No. 1, 6.

5) V. Majer: Bases of Nuclear Ghemistry, SNTL (State Publishing House for Technical Literature), Praha, (1981).

6) K. Mazanec and L. Hyspecka: Hydrogen Embrittleness of Higher Parameter Structural Steels, ACADEMIA, CSAV, Praha, (1978).

7) V. Linhart: Strojnicky Casopis, 12 (1981), 345.

8) V. Pilous: Zvaranie, 34 (1985), No. 4, 99. 